\title{
Article \\ A Novel Methodology for Assessing and Modeling Manufacturing Processes
}

\author{
Jan Reschke ${ }^{1}$ and Sergio Gallego-García ${ }^{2, *(1)}$ \\ 1 Process \& Quality Management, SMS Group GmbH, 41069 Mönchengladbach, Germany; \\ jan.reschke@sms-group.com \\ 2 Industrial Engineering Technologies of the International School of Doctorate, National Distance Education \\ University (UNED), 28040 Madrid, Spain \\ * Correspondence: sgallego118@alumno.uned.es; Tel.: +34-682-880-591
}

Citation: Reschke, J.; Gallego-García, S. A Novel Methodology for Assessing and Modeling Manufacturing Processes. Appl. Sci. 2021, 11, 10117. https://doi.org/ 10.3390/app112110117

Academic Editor: Wilma Polini

Received: 9 October 2021

Accepted: 21 October 2021

Published: 28 October 2021

Publisher's Note: MDPI stays neutral with regard to jurisdictional claims in published maps and institutional affiliations.

Copyright: (c) 2021 by the authors. Licensee MDPI, Basel, Switzerland. This article is an open access article distributed under the terms and conditions of the Creative Commons Attribution (CC BY) license (https:/ / creativecommons.org/licenses/by/ $4.0 /)$.
Featured Application: The assessment and modeling of manufacturing systems for their management and control, considering all the related areas, flows, and factors involved in digital twin models for the regulation of process stability and quality with maintenance strategies.

\begin{abstract}
Historically, researchers and practitioners have often failed to consider all the areas, factors, and implications of a process within an integrated manufacturing model. Thus, the aim of this research was to propose a holistic approach to manufacturing processes in order to assess their status and performance to improve target indicators such as product quality. For this purpose, a conceptual model is designed by identifying areas, flows, and indicators that are relevant to the assessment of a manufacturing system. Moreover, using the conceptual model, manufacturing systems can be modeled considering all related flows and decision-making options in the respective areas of production, maintenance, and quality. As a result, this model serves as the basis for the integral management and control of manufacturing systems in digital twin models for the regulation of process stability and quality with maintenance strategies. Thus, an assessment based on the conceptual model improves the knowledge level of all elements involved in the manufacturing of a product according to the desired quality specifications. The continuous monitoring of all areas and flows together with the optimal strategies in the quality and maintenance areas can enable companies to increase their profitability and customer service level. In this context, the discussion section lists key decision aspects for the assessment and improvement of manufacturing systems, while also providing a methodological sequence to evaluate and improve manufacturing systems. In conclusion, the conceptual approach allows better decision making, ensuring continuous optimization along the manufacturing asset lifecycle and providing a unique selling proposition for equipment producers and service engineering suppliers, as well as for production and assembly companies.
\end{abstract}

Keywords: integrated manufacturing model; manufacturing system assessment; manufacturing process management and control; quality management; maintenance management; digital twin

\section{Introduction}

Manufacturing currently plays a key role in the global economy [1]. The market for industrial goods is changing rapidly. Therefore, companies must face the challenges of the transition from mass production to mass customization, as well as low prices for products with shorter product lifecycles [2,3]. Furthermore, turbulences in markets are no longer the exception, and they occur due to fast-changing technologies, environments, politics, societies, pandemics, and changes in the economy, such as those resulting from Industry 4.0, COVID-19, and global economic crises. Thus, the adaptability and changeability of production systems have become key features for manufacturing [3]. In this regard, Industry 4.0 pursues autonomous decision making, interoperability, agility, flexibility, efficiency, and cost reductions [4]. Moreover, in order to improve their competitiveness and ability 
to make optimal decisions, companies need to effectively adapt to new market requirements by rethinking their production process with digital technologies [5]. In this context, with the rapid development of electric and electronic technology, information technology, and advanced manufacturing technology, production systems can be transformed from digital to intelligent [6], where an integration of products and machines in interconnected physical and digital processes combined with computing capabilities can be realized [7]. Therefore, in the future, it is to be expected that cyber-physical production systems (CPPS) will dominate manufacturing, providing new functionalities to the management processes, as well as to manufacturing and management systems supporting organizations in their decision-making capabilities [7]. As a result of this enormous potential, the smart factory concept is widely discussed [6] by academia, industry, and governments, and it has been widely applied in manufacturing due to its potential benefits to society, economy, energy, and environment, especially manufacturing [8]. However, the standards for smart factory implementation have not yet been established [6]. With feedback loops, CPPSs enable close interaction between the cyber and physical components through human-computer interaction interfaces [8]. The joint effect of decisions belonging to various production areas which are traditionally considered in isolation, such as logistics, maintenance, and quality, is difficult to predict [9]. For this purpose, digital twins (DTs) have been proven to be useful in supporting the evaluation and control of manufacturing entities as for supporting decision making together with predictive engineering leading to the capability to choose the best available option that optimizes target objectives for a given set of potential future scenarios [9].

Despite the great developments in technology over the last few decades, industrial processes present limitations in modeling and simulating manufacturing systems to assess process feasibility [10]. During the last two decades, several modeling methods and methodologies have been used for modeling, analyzing, and designing different aspects of manufacturing systems. Until recently, there has been no modeling method or methodology that can be used to model, analyze, and design complex manufacturing systems completely or support most phases of these complex systems [11]. There are many studies referring to models for the assessment of specific operation steps and their influence on the final product; however, there is still no model on how all areas and parameters of each single unit affect and interact within the whole manufacturing system [10]. Most modeling methods available are no more than static graphical representations and are not well defined. Thus, the models produced are open to misinterpretation and inconsistencies. Modeling needs a method that is simple and able to support different levels of abstraction. Analysts and designers need to model the basic manufacturing operations, as well as the relevant management decision and information systems. Most authors agree that no one technique can model the functional, information, dynamic behavior, and decisions aspects of systems [11].

In this context, for modeling a manufacturing system, one needs to consider its characteristics. In manufacturing processes, personal capacity, material, and infrastructure are transformed into products [12] under consideration of costs, time, and resources [13]. A manufacturing process depends on several flows, and the process depends inevitably on these flows to operate [14]. In the 1960s, Forrester proposed a methodology called "industrial dynamics" for the modeling and simulation of dynamic models by studying the characteristics of the information feedback of industrial systems based on six types of flows: information, orders, materials, money, staff, and equipment [15]. Moreover, in many cases, production efficiency is described considering four resources: energy resources, material resources in terms of raw materials, auxiliary materials, and supplies, human resources as the required human labor, and financial resources as the operating costs and investments for operating equipment, infrastructure, and buildings [13]. In this regard, the first description of bottlenecks in a business context was done by Gutenberg (1976) [12]. He identified bottlenecks as the resource of a company that only can be utilized until a certain threshold. The resource with the lowest threshold limits the performance of the 
overall system. Moreover, the American Production and Inventory Control Society (APICS) defines a bottleneck as an asset, a function, a department, or a resource whose capacity is smaller than or equal to the faced demand [16]. These definitions can be applied to all company processes.

Another modeling methodology is based on the input, control, mechanism, and output information concepts. With this model, it is then easy to identify the static status and elements with a product interface model (product representation) and a manufacturing data model (manufacturing representation) [17]. Furthermore, the elements of manufacturing systems can be also allocated to different hierarchical levels of the manufacturing systems, as well as structured levels (micro (single machines, work pieces, and processes), meso (process chains), and macro (factory)) for multilevel modeling, allowing interface and relationship analysis between factors [18]. In addition, to be able to control an industrial process, it is necessary to know the relationship between raw materials, process settings, and end-product results. Predictive modeling methodologies such as white-box modeling, black-box modeling, or hybrid models are providing efficient ways to study the complexities of manufacturing interactions with the simultaneous analysis of multiple factors and the development of in-built learning processes [19]. Other models are based on representing the process knowledge by means of elements understandable for any person without process or technology expertise. All the concepts are based on the description of situations that can occur during the execution of a manufacturing process. This model is based on the description of states that can be identified in a manufacturing process (situations), the task to be performed in each situation (actions), and the rules to determine the next situation after a task is executed (decisions) [20].

Furthermore, modeling based on the digital twin concept is limited, due to its novel nature with very few studies applying the use of a digital twin to production systems and manufacturing environments as they are mainly focused on highlighting its potential capabilities and benefits for the manufacturing production system, rather than analysis of the manufacturing process and integration with other dependable features such as production chains and material flows with a holistic approach based on real-time system information [21]. Regulation and control of many different process parameters using digital twins is a future research need [22] as it supports the control, optimization, and security level of manufacturing operations by reducing the variability of products thanks, for instance, to closed-loop response, blockchain, and expert systems [23].

In summary, the scientific community has proposed many manufacturing analyses based on different parameters; however, an integrated model is not provided [17]. In this context, several models have been developed to conceptualize manufacturing processes in a generic form. The goals of these models were always to secure process stability, thereby enabling the production system to reach its goals. Although new technologies are available, their integration with existing manufacturing systems is a challenging issue for developing real applications [24]. Despite the described evolution of industrial processes, the management and control of manufacturing systems have not developed the existing manufacturing models in order to consider all relevant factors in the fourth industrial revolution and the influence of key indicators of manufacturing quality and performance. Therefore, the new elements, relevant factors, and systems of the Third and Fourth Industrial Revolutions are not fully integrated in a model to provide a framework that allows for the management and control of a manufacturing processes in both present-day and future manufacturing systems.

Today, the control of manufacturing processes is a challenge for researchers and practitioners; however, many models for the manufacturing process and quality control are based on hardware quantity and quality, without paying attention to information flows, money flows, and energy flows, which have a significant influence on key indicators but are not integrated in a manufacturing model. Areas, parameters, and their study are key for successful planning and control, as well as for the optimization of target indicators. However, researchers often fail to holistically consider all the related factors 
and implications of a process within an integrated model. Thus, the aim of this research was to propose a holistic approach for manufacturing processes to assess the status of a manufacturing system, as well as the impact of changes on target indicators. This ensures continuous optimization along the machine lifecycle, providing a USP (unique selling proposition) for equipment producers, service engineering suppliers, and production and assembly companies. In conclusion, the proposed approach enables companies to increase their profitability and customer service level.

Thus, we need to model self-organized manufacturing systems, deduce their dynamic behavior, and develop appropriate control methods. However, the theories on self-organized systems are not mature, and the complex system research remains a hot topic [25]. To solve these issues, there is a need for an integrated manufacturing system that can address all interactions and interrelationships [26]. This lack of integration imposes a limitation for developing manufacturing digital twins [10]. Integration is important due to the necessity of quick responses to customer expectations, and it should connect components, enabling their communication [26].

Digital twins can play a key role in combining the related physical and virtual entities into an efficient cyber-physical production system [27]. The novel methodological approach pursues to serve as a basis framework to develop digital twin models for improving the overall performance in manufacturing systems together with simulation techniques, data analysis, and artificial intelligence, as well as machine learning and blockchain technology. The digital twin concept applied to manufacturing systems can enable real-time monitoring and control, higher efficiency and safety, the effective use of predictive maintenance, and the simulation of scenarios and risk assessment for better decision making [27].

The aim of this study was to provide a conceptual model that enables the assessment of manufacturing operations with transparency regarding the areas, flows, and factors. The goal of the model is to satisfy product quality requirements with excellence in operational efficiency. Moreover, the conceptual model seeks to serve as a basis for digital twin models and systems for assessing, managing, monitoring, and improving decision making in manufacturing systems. Furthermore, there are in the literature integrated manufacturing models; however, the focus on different areas, flows, and parameters provides the novelty of the presented model. The model includes various flows from the literature, while adding the energy flow, the maintenance aspects, the different regulation elements in the order flow, as well as adding the consideration of the manufacturing process itself to the "industrial dynamics" methodology proposed by Forrester. Furthermore, it increases the resources to be considered, monitored, and assessed defined by Gutenberg. The methodology developed is a natural evolution of the methodological frameworks created for the Second and the beginning of the Third Industrial Revolution to a modeling framework toward the Fourth Industrial Revolution. As a result, the proposed methodology details the order flow considering more managerial aspects that can regulate the manufacturing process and, therefore, the complete system. When comparing the proposed model with more recent approaches, these have a static assessment status, a level-oriented approach, a data- and AI-focused approach, or a dynamic approach; however, none of them provide a potential evaluation of all areas, flows, and elements interacting in all manufacturing systems nor the potential regulation mechanisms to control and improve the system with an integrated, dynamic, and scalable approach. Therefore, this research provides a needed framework to subsequently initiate the level-oriented and data-oriented approaches or to perform a static snapshot analysis.

Lastly, considering the above-mentioned arguments, the integrated manufacturing process model represents a novel approach to serve as a guide model for improving process management and related target indicators. Furthermore, knowledge of the impacts of flows and their factors on target indicators and stability is helpful, as this fundamental information allows one to develop maintenance and quality plans, which enable the prediction of critical factors in the process. This makes it possible to reduce operational risks by generating preventive maintenance plans for the different flows related to the manu- 
facturing process. Accordingly, the study provides a conceptual model that can support the activities of equipment producers, service engineering suppliers, and production and assembly companies.

\section{Methodology, Fundamentals, and Materials}

\subsection{Methodology}

In this paper, the methodological approach is as follows:

- Literature research on the manufacturing process, process stability, quality management and control, maintenance management, manufacturing elements, flows, parameters, system dynamics, simulation, and the integrated manufacturing model.

- Development of a conceptual model as an integrated manufacturing model with the goal of serving as a framework for assessing and modeling the manufacturing process to support the management, control, and decision making for managerial and technical positions within industrial organizations.

- Interpretation of results and derivation of implications and use cases for managers and technicians.

- Critical reflection of the research performed and outlook of potential future research based on the findings of paper.

\subsection{Resources and Flows Associated with the Manufacturing Process}

A process according to ISO (International Organization for Standardization) 9000 (2015) is defined as a set of mutually related activities that use inputs to provide an intended result [28]. The purpose of these tasks is to transform input into output [14]. In manufacturing processes, personal capacity, material, and infrastructure are transformed into products [12] under the consideration of costs, time, and resources. Products can be tangible, intangible, or hybrid [14].

The so-called three Ms, "man, material, and machine", are fundamental production factors that Gutenberg identified in the late 1960s. In many cases, production efficiency is described considering four resources: energy resources, material resources in terms of raw materials, auxiliary materials, and supplies, human resources as the required human labor, and financial resources as the operating costs and investments for operating equipment, infrastructure, and buildings [13]. To produce physical products, various resources are needed: material resources [14] corresponding to raw materials, components or semifinished products, and consumables in general, human resources for the use of direct labor, for example, who physically elaborate the products, as well as intervene in the direction, supervision, and control of production processes [14], physical resources corresponding to the use of the industrial warehouse, machinery, and tools, as well as tools in general, i.e., all the necessary infrastructure to carry out the production processes [14], energy resources, such as gas and electricity, and information flow through communication resources, which enables interconnection among remote databases and the receiving and transmission of information from the production process, which acts as a basis for the production process, such as drawings, process descriptions, manufacturing parameters, or the planning of manufacturing orders. This flow of information is synchronized with the purchased material and is used for processing [14].

\subsection{Manufacturing System and Quality}

The manufacturing system is an integration of resources that can carry out one or more production activities, and it is influenced by many different factors [1]. Manufacturing systems in the current scope are systems that perform one step in the production chain with one specific process. They all have in common that they process material in order to give it a new functionality. The productivity and reliability of such manufacturing systems increase with each generation of machines and their control technology. Suppliers focus on more robust components and integrate faster actuators where possible. New sensors are applied to enhance the control of subsystems and to enable faster synchronized 
action of all components in the machine. In this way, new manufacturing systems better follow the intended given parameters [29]. The sustainable market success of products requires an increase in quality levels. The impact of missing such quality levels can lead to interruptions in the production flow or products that do not meet customer requirements. Quality is defined differently for each product. Observing the overall manufacturing process, this definition of quality can be extended to include production factors, such as use of raw material, manufacturing lead time, or personnel required. Manufacturing systems that are expected to optimize these production factors face the challenge of processing a lot of information about the manufacturing process. While current systems are optimized toward a precise execution of a given set of parameters, self-optimizing systems need to be optimized toward product quality, and this can only be achieved if expert knowledge about the process and the boundary conditions is embedded [29].

In relation to manufacturing stability, it appears that the concept of manufacturing quality is one of the pursued goals of all manufacturing systems. Quality is a product of many factors, but if the manufacturing process is properly defined and the stability limits are also correctly determined, then the probability or the risks of not achieving the target product quality can be reduced.

\section{A Novel Methodological Model for Manufacturing Processes}

\subsection{Delimitation of the Model}

Modeling is an important tool for the investigation of complex problems [13]. The modeling, analysis, and design of manufacturing systems are difficult and complex tasks for many reasons [11]. In this context, in practice, partial models are still dominant; these models consider the process elements used and implemented in the First and Second Industrial Revolutions but lack the consideration of other elements. However, many manufacturing organizations did not develop their manufacturing control models, and, as a result, many manufacturing process management and control models currently applied in practice do not have maintenance units related to systems or do not consider the maintenance of all flows necessary to maintain operations but, instead, are mainly focused on hardware, i.e., physical materials, components, and products. The current trend is to participate in large-scale exchange of data and possess a high number of information systems and software elements.

\subsection{Conceptual Model Development Steps}

A system is an arrangement of given elements, which interact with one another [30]. Selected aspects of a system or a system process are represented by models. Models are abstractions and simplifications of reality [31]. In addition, the factory is to be understood as a complex sociotechnical system, the optimal performance of which only results from the interaction of the individual elements [32]. The steps performed to develop the conceptual model for a generic manufacturing system are as follows:

1. Identification of areas and flows with influence on a manufacturing process.

2. Breakdown and classification of areas into input, process, output, or other elements; a system consists of elements, which in turn can also be viewed as systems [31].

3. Definition of the factors in each area or flow and identification of the relevant factors in each area or flow. The state of the system also includes the state of its elements [31]. In summary, the process parameters of manufacturing processes depend on the variety of the goods and process tasks [14].

4. Development of the conceptual framework for a generic manufacturing process: conceptual flow steps, status areas, regulation, variability elements, and output product.

The conceptual model seeks to provide an integrated manufacturing management system to improve decision-making processes, enabling sustainable operations with consideration of the related elements of the Fourth Industrial Revolution. As a result, production and maintenance management for manufacturing and assembly systems are holistically monitored and improved, allowing the optimization of industrial services over their lifecy- 
cle. Therefore, product quality can be controlled by regulating the manufacturing operation modes and variability sources with support of IT systems and communication technologies. For this purpose, a digital twin model of the manufacturing process allowing iterative modeling and simulation with real or generated data is required to utilize all the conceptual model potentials.

\subsection{Design of a Novel Methodological Model for Assessing and Modeling Manufacturing Processes}

If capacities and workload are properly planned and controlled, it is possible to synchronize planning with manufacturing in a common bottleneck approach. However, a comparison of workload and capacity only is insufficient [14]. In the same context, to manage, plan, and control a manufacturing process, monitoring and maintenance of all the areas and flows influencing the manufacturing system are required. For this purpose, a conceptual model is developed.

3.3.1. Identification of Areas and Flows That Have an Influence on the Manufacturing Process

A manufacturing process depends on several flows and the inevitability of these flows to operate [14]. The flows can be of different nature, and not all flows that are to be described interact with all manufacturing processes. The potential flows related to a manufacturing process have evolved over the industrial revolutions. Each flow has a set of operational performance indicators that determine the effectiveness and efficiency of the flow. Furthermore, if the flow does not work or its functionality has a certain limitation level on its performance, it will influence the manufacturing process indicators and, therefore, its stability and capability to produce at the required quality level. Therefore, the flows involved in the manufacturing process, as well as the relevant factors within the flows, are a relevant topic to be analyzed. According the literature, the following flows are considered in the research carried out:

- Money flow: The monetary flow is to be considered in any production process, as it converts inputs that have a certain monetary value into outputs with another monetary value; moreover, within the process, there are also elements used with their related costs. As a result, even in nonprofit organizations, the financial flow is considered, as it is a relevant element for operations regarding sustainability and to show the contribution of the industrial activity to society.

- Information flow: Communication is key for knowing what specific industrial process to perform and when, how, and why it should be performed. Therefore, the information flow moves with the product along its production process. Currently, information and communication technologies are becoming increasingly important with the rise of remote services [33]. A prerequisite for remote services is corresponding information and communication technology, which, today, typically includes the Internet. According to a survey by the Federal Statistical Office, $89 \%$ of all German manufacturing companies were already connected to the Internet with a broadband connection in 2012, and, in companies with more than 50 employees, this figure was even higher than $99 \%$ [33].

- Material flow: This includes the physical movement of raw materials, semifinished products, and finished products.

- Capital equipment flow: This refers to the material resources needed to perform operations, such as tools and shelves to place materials.

- Energy flow: Since the introduction of electricity in industrial processes, energy supply has become a key aspect for the stability of the production process.

- Human resource flow: Although automation has developed in recent decades, manual activities and assembly processes are still widespread. Moreover, human resources are key, as human activity is required in monitoring and decision-making functions even in assisted and automated processes. This especially applies to the resource 
management in engineering, where it is important to achieve high productivity and efficiency to handle the bottleneck of engineers [14].

- Order flow: The orders are the effects of decisions that have not been executed in flows of other flows, such as material, money, personnel, capital equipment [15], and energy flows.

- Maintenance management and control: The area related to the preservation of the functionality of all the flows and areas involved in the manufacturing process. This controls the flow of spare parts for manufacturing assets.

- Manufacturing process: The area related to the activities performed in the production process with the technical parameters for processing an input into an output.

- Quality management and control: The area related to quality with a focus on the end customer.

\subsubsection{Manufacturing Process Model}

This subsection aims to break down the elements, areas, and flows of a manufacturing process into input, process, regulation mechanisms, and output or other areas, as shown in Figure 1.

- Input: Information, material, money, and energy flows are inputs that enable the initiation of the manufacturing processes.

- Process: During the manufacturing process, other factors are relevant, such as human resource functions, the information flow received from the IT systems, and communication technologies. To ensure that this information flow reaches the manufacturing asset and the product, the maintenance activities for hardware and software components, as well as the maintenance of IT and communication systems, are key. Maintenance during the process provides condition monitoring of the asset and process, and it enables the realization of corrective maintenance activities.

- Regulation mechanisms: These elements provide the areas whose function is to optimize and stabilize the process in future operating times. These are maintenance management and control, quality management and control, process design and optimization, and the order flows that are the decisions that influence the system from both current and future states.

- Lastly, the output areas are the information, material, money, and energy flows obtained because of the manufacturing process and the related transformation from the input to the output item. Furthermore, an important output is the quality control of output according to quality requirements. Moreover, the main goal of logistics is to be able to provide the right products in the right quantity and quality with full information at the right time and at the right place [34].

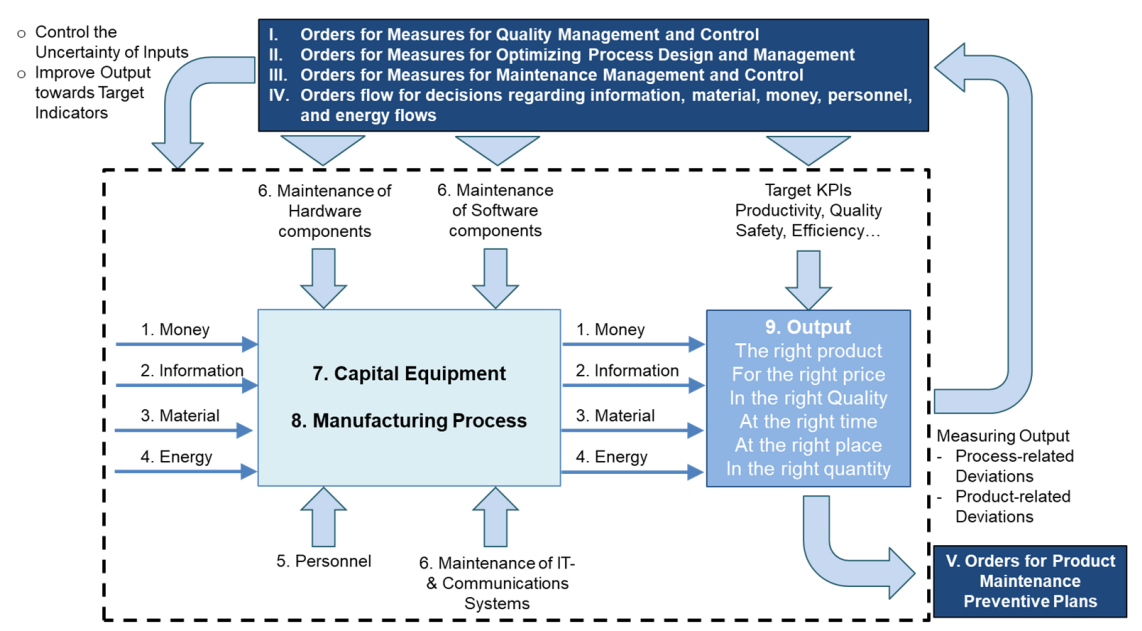

Figure 1. Diagram of the manufacturing process of input-output: areas and flows including decisions/orders (own elaboration). 
Figure 1 describes the described manufacturing process input-output diagram in which the different areas can be identified.

\subsubsection{Factors and Parameters in Each Area of the Manufacturing Process}

Following the classification of areas, the identification of factors influencing the manufacturing process within each of the areas is carried out. Forrester proposed a methodology for the simulation of dynamic models by studying the characteristics of the information feedback of industrial systems to understand how the organizational structure, amplification in policies, and time delays interact to influence the company's performance. According to this methodology, organizations are considered as systems with six types of flows: information, orders, materials, money, staff, and equipment [15]. In this research, the energy flow is also included. Moreover, as the process and certain maintenance activities influence the real-time execution of the manufacturing activity, these two areas are also considered. Lastly, the output indicators are also considered as an area. Furthermore, the order flow is the decision-making area; therefore, it is treated separately, as it does not define the current state but the decisions influencing the future states of the manufacturing system. Therefore, the representative manufacturing process factors and parameters shown in Figure 1 related to the abovementioned areas and flows are as follows:

1. Money flow: Indicators that describe the cost of the input item, value of the output item, and cost of resources used in the manufacturing process operation and maintenance. The aim of a company or an industry is to achieve output targets with the lowest possible financial resources in terms of investment and operating costs. Accordingly, it does not make sense to install excess capacities and, thus, make high investments in equipment, systems, buildings, and the necessary infrastructure. The goal is good overall equipment effectiveness (OEE). Moreover, particular attention is paid to the availability of the systems, as low system availability is in many cases the trigger for investments. High operating costs due to high energy costs or high maintenance costs can also trigger investments [13].

2. Information flow: Parameters are related to the availability of input, process, and output data related to the product, the manufacturing process, or the information and communication technology infrastructure. The availability of information flow depends on oral communication, paper or e-mail communication, or today's more usual communication systems information. For the latter, availability depends on the capability to transmit, receive, and gather data, and those activities normally depend on the network signal in use for these activities.

3. Material flow: Material efficiency in raw materials, consumables, and supplies is an important factor, as the cost of materials is considerable within the profit and loss account of a company in the manufacturing sector, accounting for around or even over $40 \%$ of the total manufacturing costs. In a German study, manufacturing companies surveyed estimated their potential for material savings to be an average of $7 \%$. A large part of the material saving potential can be found within the production processes, and specifically in the material losses during launching processes. Overproduction has enormous material efficiency potential [13]. Indicators in this flow are related to two areas:

(a) Input material: the quality of material properties, stock levels, availability of materials, logistics flow reliability, replenishment times, etc.

(b) Output material: the quality of material properties, availability of materials, material losses, etc.

4. Energy flow: Indicators in this flow are related to the production, consumption, and use efficiency of energy in the manufacturing process. Efficiency in the use of energy is an important factor, as energy consumption for industry in an industrialized country is considerable, accounting, for instance, for $30 \%$ of final energy consumption in Germany, making the industry the largest consumer of final energy [13]. 
5. Personnel resource flow: Parameters such as punctuality, availability, the absence rate, the illness rate, the accident rate, the motivation rate, and the divergence between the target and as-is personnel quantity are factors relevant to the manufacturing process. The working person will continue to be the focus in the production of the future, but the requirements will shift [35]. Future qualification requirements for specialists in production are an important factor in order to guide knowledge [32].

6. Maintenance area: This refers to maintenance in the sense of condition monitoring of the process and the manufacturing assets and operating material used during the process. In this sense, parameters such as mean time 'til repair (MTTR) or mean time between failures (MTBF), and reaction times for any disturbance are factors that are important to the stability of the manufacturing process. Moreover, maintenance does not only refer to hardware but also to software and data elements, as well as the maintenance of IT systems and communication technologies that provide information to execute, control, and monitor the process.

7. Manufacturing process area: The stability of the processes is also a prerequisite for low rejection rates. Optimizing cutting processes, thereby reducing waste, for instance, is another method by which efficiency can be increased [13].

8. Capital equipment flow: Quantity of machine groups, number of machines, acquisition of new machines, tools in use, etc. OEE (overall equipment effectiveness) is the main indicator composed of availability, performance, and quality. Capacity utilization is an additional factor. The condition of the manufacturing asset components and the related maintenance activities in terms of time, quality, adherence to plan, etc. are also important. This factor encompasses the operational material means; these are the quantity, availability, and condition of the tools, shelves, etc. used within the manufacturing operations.

9. Output area: This refers to the values of the factors and parameters that assess whether the manufacturing process is reaching its desirable output. From the different types of output, there are quality requirement indicators, including legal compliance, logistics indicators, and economic indicators.

Order flow: This flow represents the decisions of the system, such as the orders for procurement material, finished products, new employees, new machines, and plant space. This depends on the market demand, the decision to perform certain requests of customers, the current state of the system, and decisions regarding the management system, such as maintenance policy decisions, quality and process management, and control methods.

For the nine areas depicted in Figure 2, a representative selection of factors related to them is given. For example, the money flow area has several factors and three of them are: revenues, expenses, and investments. On the basis of these, the monetary status that enables the process can be assessed. Moreover, for the maintenance area, there are also various factors including: the maintenance of hardware components of the manufacturing assets, the maintenance of other material operating resources, the maintenance of software elements and IT communication systems, and the management of spare parts. 


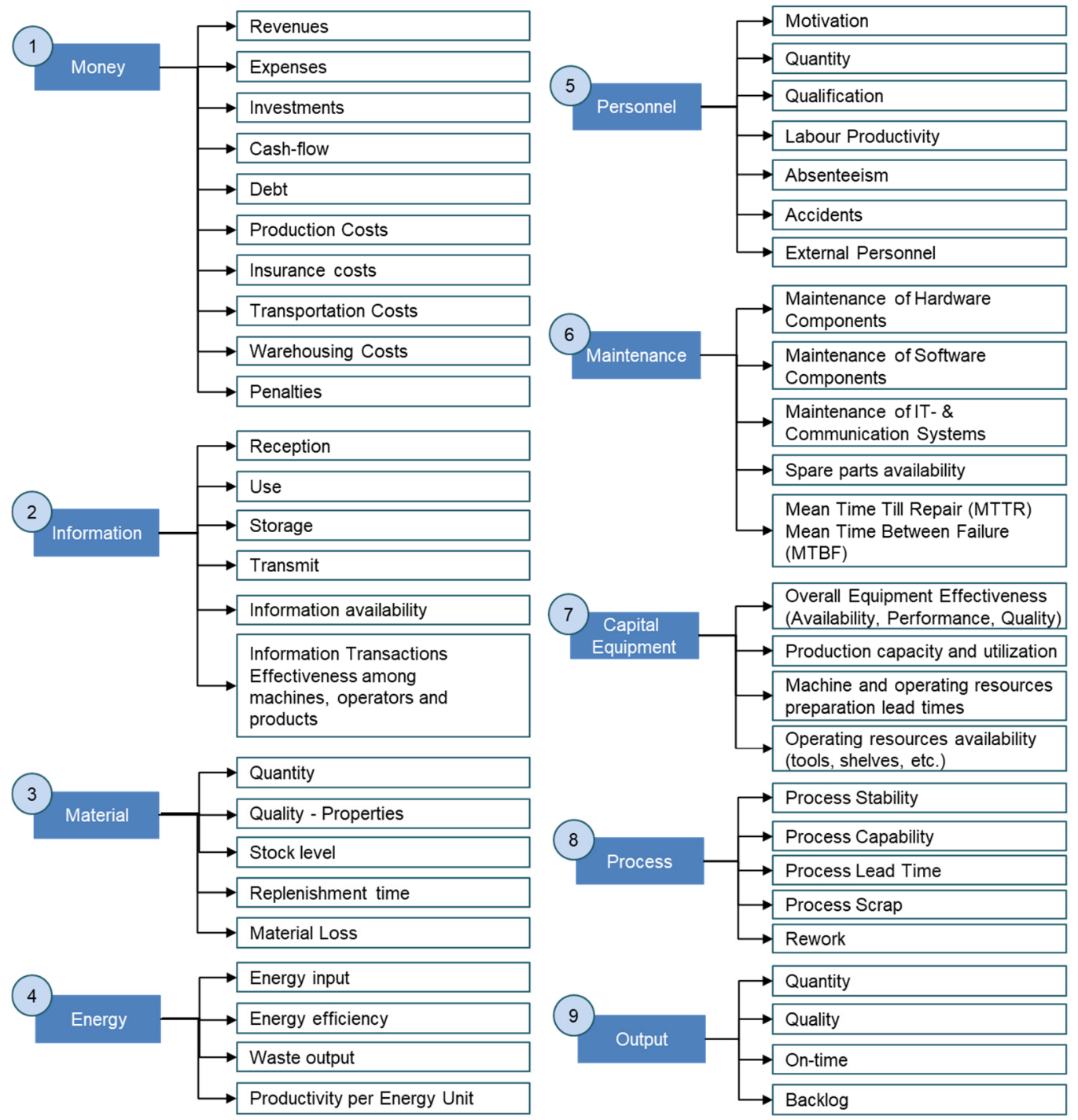

Figure 2. Manufacturing process factors and parameters (own elaboration).

\subsection{Manufacturing System Assessment}

Given a manufacturing system consisting of several process lines and various manufacturing processes in each process line, the analysis and assessment of the current state and of the system dynamics can be performed by following the developed conceptual model. Therefore, Figure 3 shows how a manufacturing system can be determined by the indicators of the manufacturing processes within it. By doing so, within each process, the related areas, flows, and parameters are to be identified, measured, and controlled in order to assess the actual process status and to define the future management and monitoring strategies for the specific process. This latter definition can be performed by following a bottom-up approach or as a disaggregation of the global manufacturing system target indicators, i.e., a top-down approach. Moreover, the assessment provides a syndication of which areas and flows are limiting target indicators such as the output or the quality parameters due to for instance the money flow due to the nonavailability of cashflow or the energy flow due to an overheating process in a thermal treatment. 


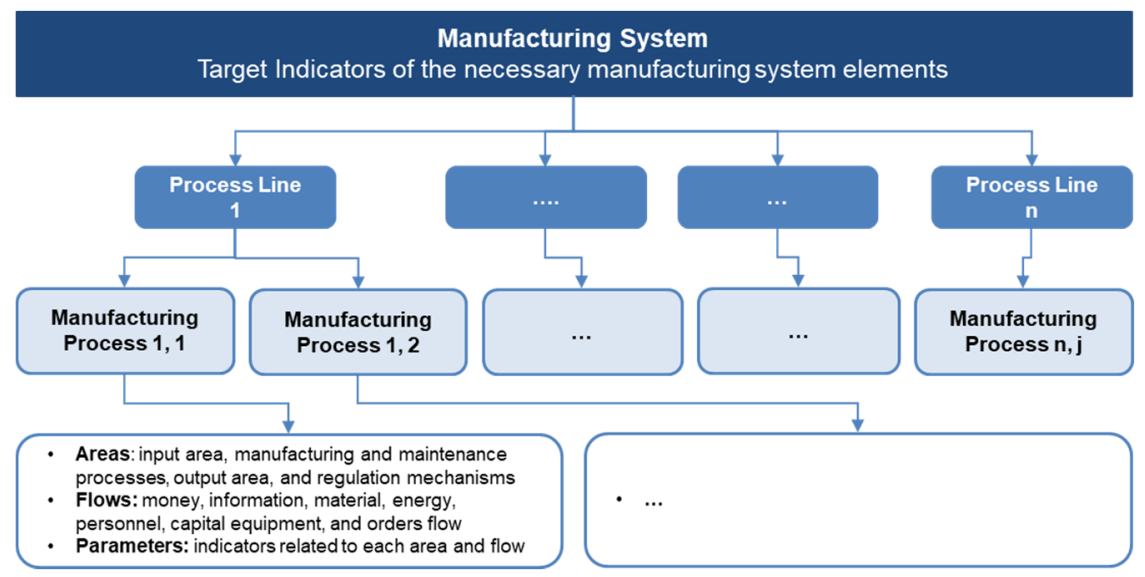

Figure 3. Manufacturing system assessment (own elaboration).

Furthermore, this manufacturing view of the system is required for further development as it provides a complete overview of the whole manufacturing system and its necessary elements to meet the expected industrial results. Lastly, it is key to point out that this analysis and assessment methodology can provide the basis foundational input for further developments for digital twin models of the manufacturing system and improvements based on data analysis and artificial intelligence.

\section{Discussion}

Today, many manufacturing systems have difficulties in identifying where the lack of quality, availability, performance, and efficiency comes from when there is a disruption. Efficiency or performance of a production line is, in many occasions, calculated on the basis of experience values or only on machine availability without considering other disruption sources, such as the Internet, systems, or energy availability. Furthermore, most organizations have separate "kingdoms" as organizational silos with functions related to the manufacturing system that are distributed among departments and fragmented with divergent goals. As a result, there are normally functional gaps between areas; that is, it is not known who is responsible for the disruption, what its cause is, and how it should be analyzed. In addition, manufacturing organizations normally focus on planning the material flow and procurement, as well as the capacity of capital equipment; however, the planning of other resources is equally not considered according to the orders to be produced and the effect on the overall manufacturing system. In this context, product preventive maintenance plans are normally designed from the beginning, and they are usually not considered issues during the production process (if they are considered as such, they are regarded as reactive only). As a result, maintenance plans are not aligned with their manufacturing or assembly process and, therefore, can be over- or under-dimensioned.

The previously described situation occurs due to many reasons, among which are the multiple systems, various energy sources, the increasing industrial communication networks, and elements with communication capabilities. This complexity is greater than ever and will continue to grow in the Fourth Industrial Revolution. This challenge is also a great opportunity, because condition monitoring with predictive analytics and big data can enhance the capabilities of quality, maintenance, and production management and control toward digital twins enabling the smart factory concept.

According to the developed conceptual model, an organization must decide on its manufacturing system in four areas: focus, scope, organizational structure, and development strategy as shown in Figure 4 


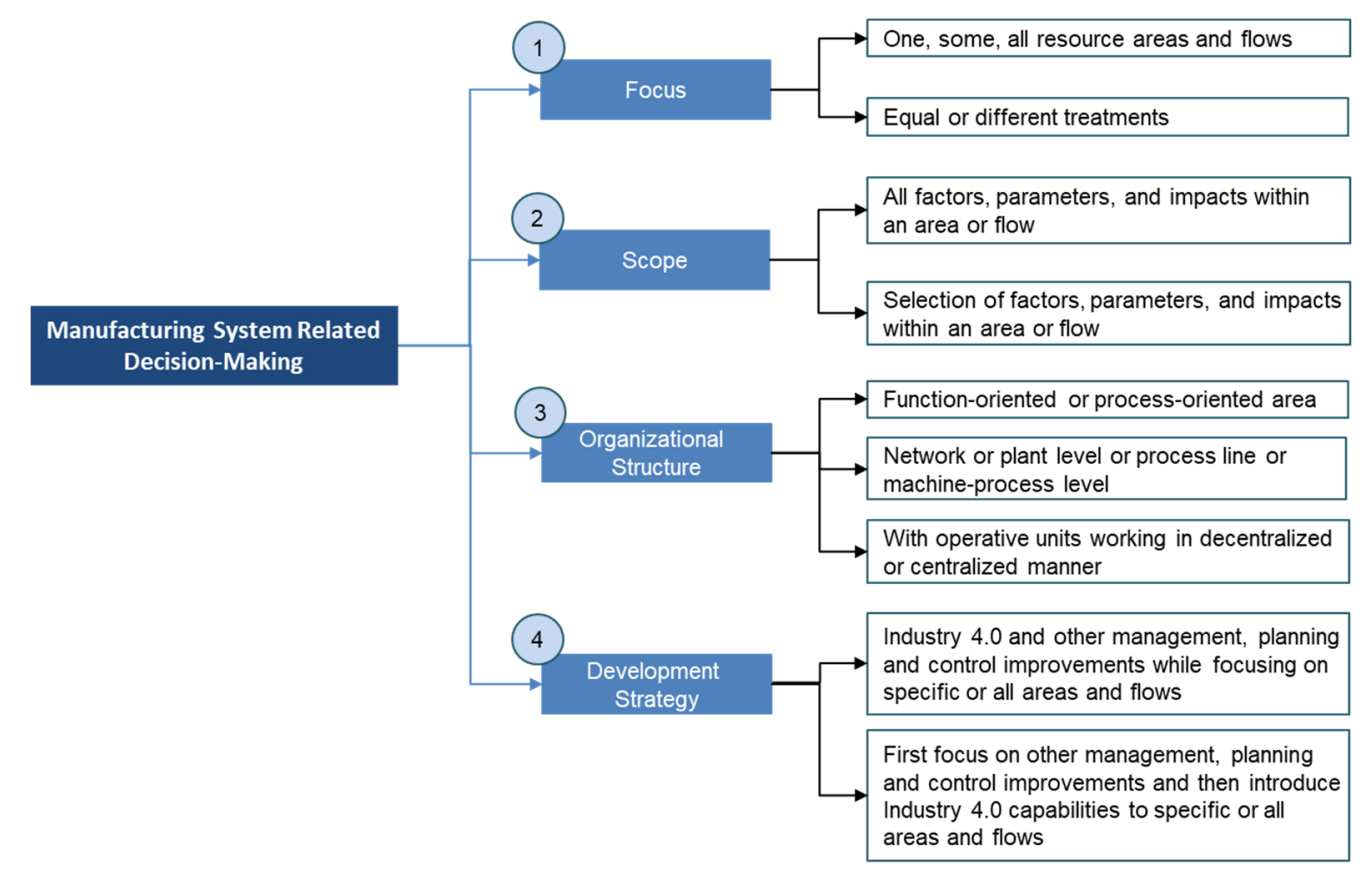

Figure 4. Manufacturing system and related decision-making options (own elaboration).

The following must be decided regarding its focus:

- Decision to focus on one or some specific resource areas;

- Decision to treat all areas with an impact on the manufacturing process equally.

Moreover, a company must decide on the scope in each area by making the following decisions:

- Decision to analyze all factors and parameters within the area, as well as the interrelationships among them and the impacts that they have on the overall system;

- Decision to consider a selection of the factors, parameters, and impacts within each area.

In addition, a company decides how to include the manufacturing process control, assessment, and improvement in their functional structure as follows:

- Within the function-oriented or process-oriented area;

- At the network or plant level or line or machine level;

- With operative units working in decentralized or centralized manner.

Lastly, the development strategy for the manufacturing process must consider the following decisions:

- Decision to progress toward Industry 4.0 and quality, maintenance, and production logistics improvements while focusing on specific or all areas;

- Decision to first focus on quality, maintenance, and production logistics improvements and then progress toward introducing Industry 4.0 capabilities to specific or all areas.

Independently of these decisions, the steps presented below in Figure 5 can be followed to implement the conceptual model. 


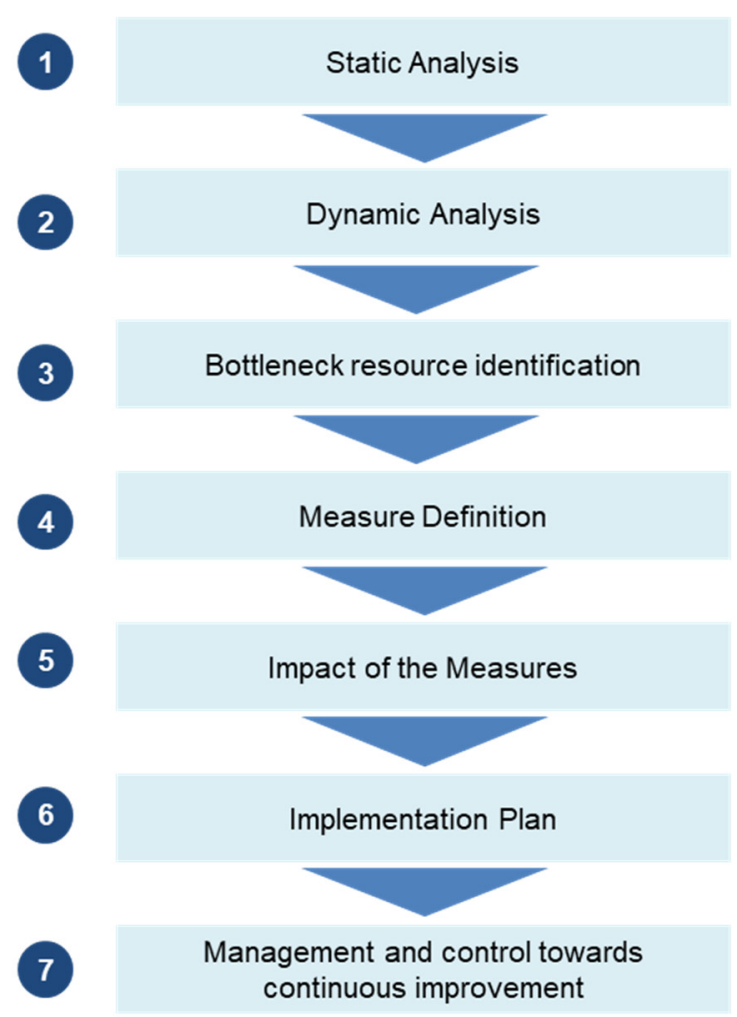

\section{Examples}

- Map the Production Process

Input, process, and output

Product Quality

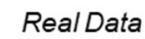

Timeline and Milestones

Communication and Training

Figure 5. Methodology to assess and improve manufacturing systems (own elaboration).

Lastly, the final steps of the developed framework with the aim of providing a methodology to assess and improve manufacturing systems are as follows:

1. Static analysis: This consists of mapping of the production flow, determining the manufacturing process (input areas, process parameters, and output areas), classifying areas and factors into normal, relevant, and indispensable areas or factors, identifying the product and its quality characteristics (functionalities of the final product and value-added to the end customer), relating areas and factors of the manufacturing process with product functionalities, and associating areas and factors with organizational structure.

2. Dynamic analysis: This is an analysis of the manufacturing process to determine operational limitations for sustainable operations. This can be performed with real data and/or with iterative simulation of the manufacturing systems. This step defines how the system determines the decisions and actions over time. Moreover, it helps to identify all potential disturbances or variability sources of the areas and factors.

3. Bottleneck resource identification for manufacturing system goals: The conceptual model can be used as series with parallel elements and expected availabilities that can be applied for managing and planning purposes, as well as identify the production output efficiency and the associated risks. Moreover, by applying predictive analytics and maintenance based on real data, the availability values can increase their accuracy. Taking into account the goals and the impact level of the different variability sources, priorities can be defined. For instance, if information availability is only secure at $80 \%$ due to IT systems disruption while the availability of all other areas is ensured at $99 \%$, then all other areas are wasting resources from $80 \%$ to $99 \%$.

4. After determining which resource areas and factors need to be improved, the next step is to identify which measures can be applied to improve the bottleneck resources to satisfy the manufacturing system goals. The measures can be classified in four different types: 
- Quality measures, such as quality management and control methods and systems;

- Maintenance measures, such as maintenance management and control methods and systems;

- Production logistics measures, such as production management and control methods and systems;

- Improving resource areas and their capabilities: money, information, material, energy, personnel, and capital equipment.

5. The impact of the measures on the required time and economic efforts is determined, and an analysis of risks of their implementation for the global manufacturing system is conducted. After this analysis, decisions are to be made, and the measures are to be defined.

6. An implementation plan, including communication and training, is initiated.

7. It is necessary to plan how the new measures and their interrelationships within the system will be managed and controlled.

All these steps are combined with sensors, simulations, and a manufacturing system digital twin with all areas, factors, parameters, and interrelationships. Moreover, by adding condition monitoring at the different levels of the network, plant, production line, manufacturing cell, and machine, transparency can be achieved, enabling quick identification of the system state, bottlenecks, and potential measures and risks for improvement, which facilitates progress toward achieving manufacturing system goals.

\section{Conclusions}

This section is divided into theoretical and managerial conclusions, in addition to an explanation of the limitations of the research performed and a description of the potential future research derived from the findings.

Theoretical conclusions: The research work developed a holistic approach for the assessment of the status and performance of manufacturing systems and processes, providing steps as guidelines to follow in order to successfully apply the approach in real manufacturing systems. For that purpose, a new concept was generated by developing the state-of-the-art methodologies and approaches by considering areas, factors, parameters, and their interrelationships defined for a generic manufacturing system.

Regarding managerial conclusions, the current challenges and opportunities for manufacturing systems were described and the need for an integrated model was exposed in which the relevant changes related to manufacturing systems through the industrial revolutions were identified as an opportunity to develop manufacturing modeling methodologies that can enable the transition and implementation of technologies and capabilities of the Fourth Industrial Revolution. As a result, the conceptual model provides a framework for building digital models thanks to the manufacturing overview given. Moreover, the novel methodology approach applied to digital twin models can be a key tool in managerial decision making.

Furthermore, the research work had limitations as it was not developed at the operative level and for specific cases, while it was also not proven in any company.

Future research based on this research could focus on the following:

- Transferring this research method to real production systems and applying it as a digital twin tool or an assistance tool for sales, production, quality, and maintenance leaders by centralizing all data related to the manufacturing system, thereby allowing the simulation of what-if scenarios, as well as for the monitoring and assessment of the manufacturing system state.

- Improving the model based on implementation feedbacks, as well as applying it to production networks with several production plants.

- Including data analytics, artificial intelligence, and blockchain, as well as other Industry 4.0 advancements, into the model and its applications. 
In summary, this study showed the potential benefits of the conceptual approach, allowing better decision making for both manufacturing and assembly managers and equipment and service suppliers. This ensures continuous optimization along the manufacturing asset lifecycle. The proposed model offers a novel methodology of how manufacturing processes can be assessed, managed, and controlled in an integral way. As a result, the proposed methodology represents a useful tool for organizations and managers in order to increase their efficiency, competitiveness, and, therefore, viability over time.

Author Contributions: Conceptualization, S.G.-G.; methodology, J.R. and S.G.-G.; software and programming, S.G.-G.; validation, S.G.-G.; data analysis, S.G.-G.; writing (review and editing), S.G.-G. All authors have read and agreed to the published version of the manuscript.

Funding: This research received no external funding.

Institutional Review Board Statement: Not applicable.

Informed Consent Statement: Not applicable.

Conflicts of Interest: The authors declare no conflict of interest.

\section{References}

1. Qin, J.; Liu, Y.; Grosvenor, R. A categorical framework of manufacturing for industry 4.0 and beyond. Procedia CIRP 2016, 52, 173-178. [CrossRef]

2. Schilberg, D.; Meisen, T.; Reinhard, R. Virtual Production-The connection of the modules through the Virtual Production Intelligence. In Proceedings of the World Congress on Engineering and Computer Science, San Francisco, CA, USA, 23-25 October 2013; Volume 2, pp. 23-25.

3. Keddis, N.; Kainz, G.; Buckl, C.; Knoll, A. Towards adaptable manufacturing systems. In Proceedings of the 2013 IEEE International Conference on Industrial Technology (ICIT), Cape Town, South Africa, 23-28 February 2013; pp. 1410-1415.

4. Perales, D.P.; Valero, F.A.; García, A.B. Industry 4.0: A classification scheme. In Closing the Gap between Practice and Research in Industrial Engineering; Springer: Berlin/Heidelberg, Germany, 2018; pp. 343-350.

5. Florescu, A.; Barabas, S.A. Modeling and simulation of a flexible manufacturing system-A basic component of industry 4.0. Appl. Sci. 2020, 10, 8300. [CrossRef]

6. Chen, B.; Wan, J.; Shu, L.; Li, P.; Mukherjee, M.; Yin, B. Smart factory of industry 4.0: Key technologies, application case, and challenges. IEEE Access 2017, 6, 6505-6519. [CrossRef]

7. Cortés, C.B.Y.; Landeta, J.M.I.; Chacón, J.G.B. El entorno de la industria 4.0: Implicaciones y perspectivas futuras. Concienc. Tecnológica 2017, 54, 33-45.

8. Tao, F; Qi, Q. New IT driven service-oriented smart manufacturing: Framework and characteristics. IEEE Trans. Syst. Man Cybern. Syst. 2017, 49, 81-91. [CrossRef]

9. Magnanini, M.C.; Tolio, T.A. A model-based Digital Twin to support responsive manufacturing systems. CIRP Annals 2021. [CrossRef]

10. Alves, C.L.; De Noni, A., Jr.; Janßen, R.; Hotza, D.; Neto, J.R.; González, S.G.; Dosta, M. Integrated process simulation of porcelain stoneware manufacturing using flowsheet simulation. CIRP J. Manuf. Sci. Technol. 2021, 33, 473-487. [CrossRef]

11. Al-Ahmari, A.M.A.; Ridgway, K. An integrated modeling method to support manufacturing systems analysis and design. Comput. Ind. 1999, 38, 225-238. [CrossRef]

12. Gutenberg, E. Grundlagen der Betriebswirtschaftslehre, 22nd ed.; Springer: Berlin/Heidelberg, Germany; New York, NY, USA, 1976.

13. Ramsauer, C. Industrie 4.0-Die Produktion der Zukunft. WINGbusiness 2013, 3, 6-12.

14. Hinckeldeyn, J.; Dekkers, R.; Altfeld, N.; Kreutzfeldt, J. Bottleneck-based synchronisation of engineering and manufacturing. In Proceedings of the International Association for Management of Technology IAMOT 2010 19th International Conference on Management of Technology, Cairo, Egypt, 7-11 March 2010.

15. Forrester, J.W. Industrial Dynamics, 4th ed.; MIT Press: Cambridge, UK, 1969.

16. Blackstone, J.H. APICS Dictionary-The Standard for Excellence in the Operations Management Profession; APICS-The Association of Operations Management Dictionary: Chicago, IL, USA, 2008; pp. 1-156.

17. Skander, A.; Roucoules, L.; Meyer, J.S.K. Design and manufacturing interface modelling for manufacturing processes selection and knowledge synthesis in design. Int. J. Adv. Manuf. Technol. 2008, 37, 443-454. [CrossRef]

18. Schönemann, M.; Schmidt, C.; Herrmann, C.; Thiede, S. Multi-level modeling and simulation of manufacturing systems for lightweight automotive components. Procedia CIRP 2016, 41, 1049-1054. [CrossRef]

19. Roupas, P. Predictive modelling of dairy manufacturing processes. Int. Dairy J. 2008, 18, 741-753. [CrossRef]

20. Garcia-Crespo, A.; Ruiz-Mezcua, B.; Lopez-Cuadrado, J.L.; Gómez-Berbís, J.M. Conceptual model for semantic representation of industrial manufacturing processes. Comput. Ind. 2010, 61, 595-612. [CrossRef] 
21. Mawson, V.J.; Hughes, B.R. The development of modelling tools to improve energy efficiency in manufacturing processes and systems. J. Manuf. Syst. 2019, 51, 95-105. [CrossRef]

22. Stavropoulos, P.; Papacharalampopoulos, A.; Michail, C.K.; Chryssolouris, G. Robust Additive Manufacturing Performance through a Control Oriented Digital Twin. Metals 2021, 11, 708. [CrossRef]

23. Papacharalampopoulos, A.; Bikas, H.; Michail, C.; Stavropoulos, P. On the generation of validated manufacturing process optimization and control schemes. Procedia CIRP 2021, 96, 57-62. [CrossRef]

24. Khosravani, M.R.; Nasiri, S.; Reinicke, T. Intelligent knowledge-based system to improve injection molding process. J. Ind. Inf. Integr. 2021, 100275, 100275.

25. Wang, S.; Wan, J.; Li, D.; Zhang, C. Implementing smart factory of industrie 4.0: An outlook. Int. J. Distribut. Sens. Netw. 2016, 12, 3159805. [CrossRef]

26. Oztemel, E.; Tekez, E.K. A general framework of a reference model for intelligent integrated manufacturing systems (REMIMS). Eng. Appl. Artif. Intell. 2009, 22, 855-864. [CrossRef]

27. Bárkányi, Á.; Chován, T.; Németh, S.; Abonyi, J. Modelling for Digital Twins-Potential Role of Surrogate Models. Processes 2021, 9, 476. [CrossRef]

28. ISO 9000. 2015 Sistemas de Gestión de la Calidad_Fundamentos y Vocabulario; ISO: Geneva, Switzerland, 2015.

29. Permin, E.; Bertelsmeier, F.; Blum, M.; Bützler, J.; Haag, S.; Kuz, S.; Özdemir, D.; Stemmler, S.; Thombansen, U.; Schmitt, R.; et al. Self-optimizing production systems. Procedia CIRP 2016, 41, 417-422. [CrossRef]

30. 19226, DIN: Leittechnik, Regelungstechnik und Steuerungstechnik. Allgemeine Grundlagen, Teil 1; Deutsches Institut für Normung: Berlin, Germany, 1994.

31. Frank, U.; Giese, H.; Klein, F.; Oberschelp, O.; Schmidt, A.; Schulz, B.; Vocking, H.; Gausemeier, J. Selbstoptimierende Systeme des Maschinenbaus. Definitionen und Konzepte; Sonderforschungsbereich, Deutsche Forschungsgemeinschaft: Paderborn, Germany, 2004; p. 614.

32. Zeller, B.; Achtenhagen, C.; Först, S. Das "Internet der Dinge" in der Industriellen Produktion-Studie zu Künftigen Qualifikationserfordernissen auf Fachkräfteebene. Report FreQueNz-Früherkennung von Qualifikationserfordernissen; Forschungsinstitut Betriebliche Bildung: Bonn, Germany; Nürnberg, Germany, 2010.

33. Voigt, K.I.; Steinmann, D.I.F.; Bauer, D.I.J.; Dremel, A. Condition Monitoring als Schlüsseltechnologie-Eine Analyse der Anforderungen an Neue Geschäftsmodelle für den Remote Service; Heinz Nixdorf Institut-Universität: Paderborn, Germany, 2013.

34. Schuh, G.; Stich, V.; Wienholdt, H. Logistikmanagement; Springer: Berlin/Heidelberg, Germany, 2013.

35. Elevli, S.; Elevli, B. Performance measurement of mining equipments by utilizing OEE. Acta Montan. Slovaca 2010, 15, 95. 